\title{
Application of BIM coordination technology to HSR Changhua station
}

\author{
Weilun Lee ${ }^{\text {* }}$, Szumin Kang ${ }^{1}$, Richard Moh ${ }^{1}$, Robert Wu², Hungchang Hsieh ${ }^{3}$ and Zhehua Shu ${ }^{3}$
}

\begin{abstract}
The arising trend of building information modeling technology application with innovative and revolutionary approach has changed the workflow and deliberation in A/E/C industry. By considering the condensed schedule of the project, operation safety, and information correctness during design and construction stages, Taiwan High Speed Rail Corporation (THSRC) brings BIM technology into Changhua Station construction project. The accumulated massive information helps engineers to coordinate design information among different expertise (architecture, structure, MEP, etc.) into BIM model at earlier phases. The effectiveness of BIM coordination technology increases the design quality and reduces significantly the conflicts of various interfaces. Three-dimension visualized interface increases the problem solving efficiency. During construction stage, construction information is integrated by the model to enhance fluency of construction process among different construction sectors. Application of BIM coordination technology reduces information gap, enhances construction quality and meets the schedule.
\end{abstract}

Keywords: Building information modeling; Integration; Coordination; Visualization

\section{Background}

The HSR Changhua Station (shown as Figure 1) is a planned station of the Taiwan High Speed Rail located in Tian Zhong Township (shown as Figure 2), Changhua County. The elevated station will have two side platforms and is planned to open in 2015. The new station will significantly enhance the availability of inter-regional traffic and promote the local industrial development.

\section{Case description}

Design concept of Changhua station

1. Tian Zhong means "the center of the fields" in Chinese, Changhua is famous for its yearly flora exposition and is known as the county of flora. Therefore flora is the main design concept of Changhua high speed rail station.

2. The columns in the lobby combines the flower image, opening and stretching like flower petals. The skylight lets in natural light and the columns are placed in a way to reflect indirect light to illuminate

\footnotetext{
* Correspondence: weilun.lee@maaconsultants.com

${ }^{1}$ Moh and Associates, Inc., BIM Mgmt. \& Engr. Integration Center, Taipei, Taiwan

Full list of author information is available at the end of the article
}

the lobby. Light, structure and flower are presented in harmony.

3. Inside the station, there is a greenhouse surrounding the station. Passengers can enjoy the green view in the station. This is one of the features of Changhua station.

\section{Building information modeling}

The revolution of BIM technology has overturned the traditional civil construction workflow and process. Among traditional and innovative thinking, BIM has brought the spirit of enhanced quality and efficiency into civil and architecture industries. The application of BIM technology has provided different meanings to each phase of the whole building life cycle (shown as Figure 3).

The THSR Changhua station project incorporates BIM integration technology at the early design phase in consideration of stability and safety of the railroad operation, high standard of precision and quality, the tight schedule of construction, and other factors. The objectives of the project are (shown as Figure 4):

1. Integrate the curvatures of featured petal-like columns. 


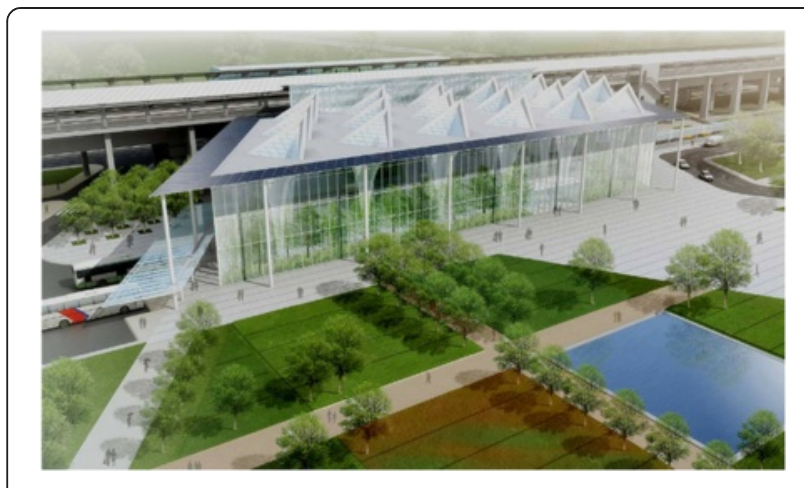

Figure 1 New HSR Changhua station.

2. Complete the project under a tight schedule. The construction period is only 31 months.

3. Incorporate BIM integration technology at the early planning phase to reduce the errors of traditional two dimensional CAD drawings so as to reduce the chances of design changes at the construction phase and to increase the overall quality of the project.

4. Provide the platform of 3D visualization to detect piping clash and thus to optimize work efficiency and to reduce jobsite problems.

5. Incorporate the information of the architecture, electrical, mechanical facilities such as facility brands, life and maintenance schedule through BIM technology to increase the operation and management efficiency.

The introduction of BIM technology has changed the workflow of traditional architecture construction. In this project, BIM technology was introduced during the detailed design phase. A great amount of data was integrated to improve the efficiency and to reduce the corrections and errors during the construction (shown as Figure 5).
Taiwan High Speed Rail Corporation found the importance of integrating design outcomes of various disciplines and took it as the priority during the planning stage of the project; and, thus, BIM technology was applied for this purpose. BIM Management and Integrating Center (BIM center) of $\mathrm{MOH}$ and Associates was invited to provide the BIM service. Architecture, structural and MEP BIM models were created based on the design of each discipline to clarify problems and to review clashes of each discipline and between different disciplines at the early stage.

\section{Discussion and evaluation \\ Application of BIM technology in design drawing integration in design phase}

Previously, two-dimensional architecture, structural and MEP drawings were combined and organized at the construction site. Frequently errors and information gap occurred while integrating those drawings of different revisions, resulting in waste of resource and decrease of productivity during late construction phase. This project adopted BIM technology (shown as Figure 6) and cloud computing interface (shown as Figure 7) at detailed design stage to assist THSRC to incorporate different types of drawings.

This interface enabled the integration of traditional 2D drawings and made it possible to manage 3D BIM models, 3D parameters, and BIM collaboration. Clash detection reports and clarification reports can be generated with the integrated BIM model. The 3D visualized communication model provides a useful tool for the examination and discussion with THSRC (shown as Figure 8).

To perform the design concept of the graceful posture of flower blossom, it is critical to integrate the curved columns with architecture curvature and MEP. The curved structural column is the featured design of this project. The steel manufacturer pre-fabricated the steel

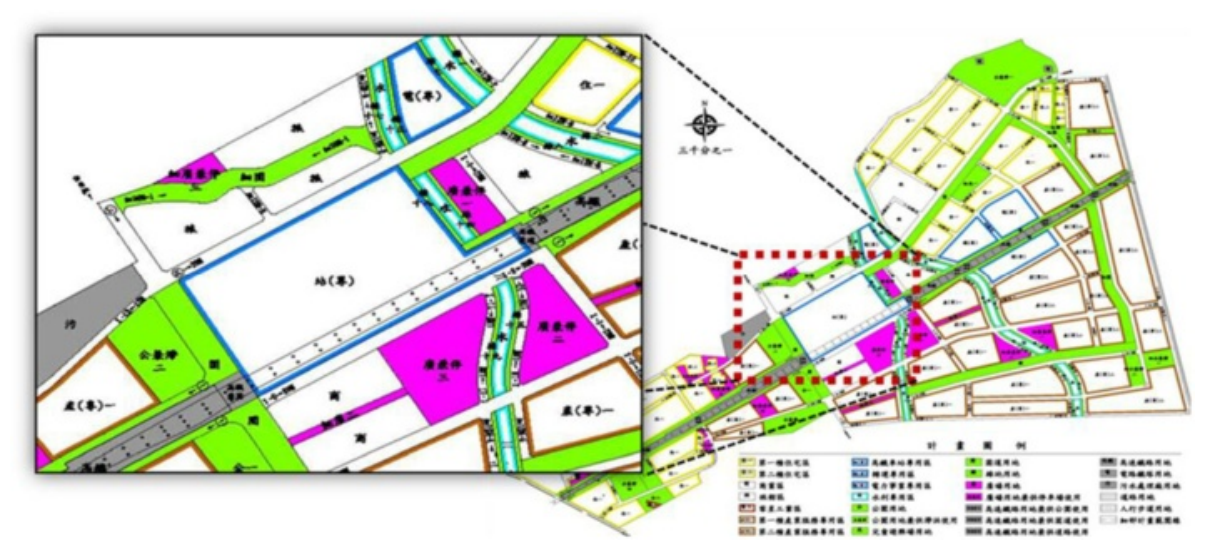

Figure 2 City planning. 


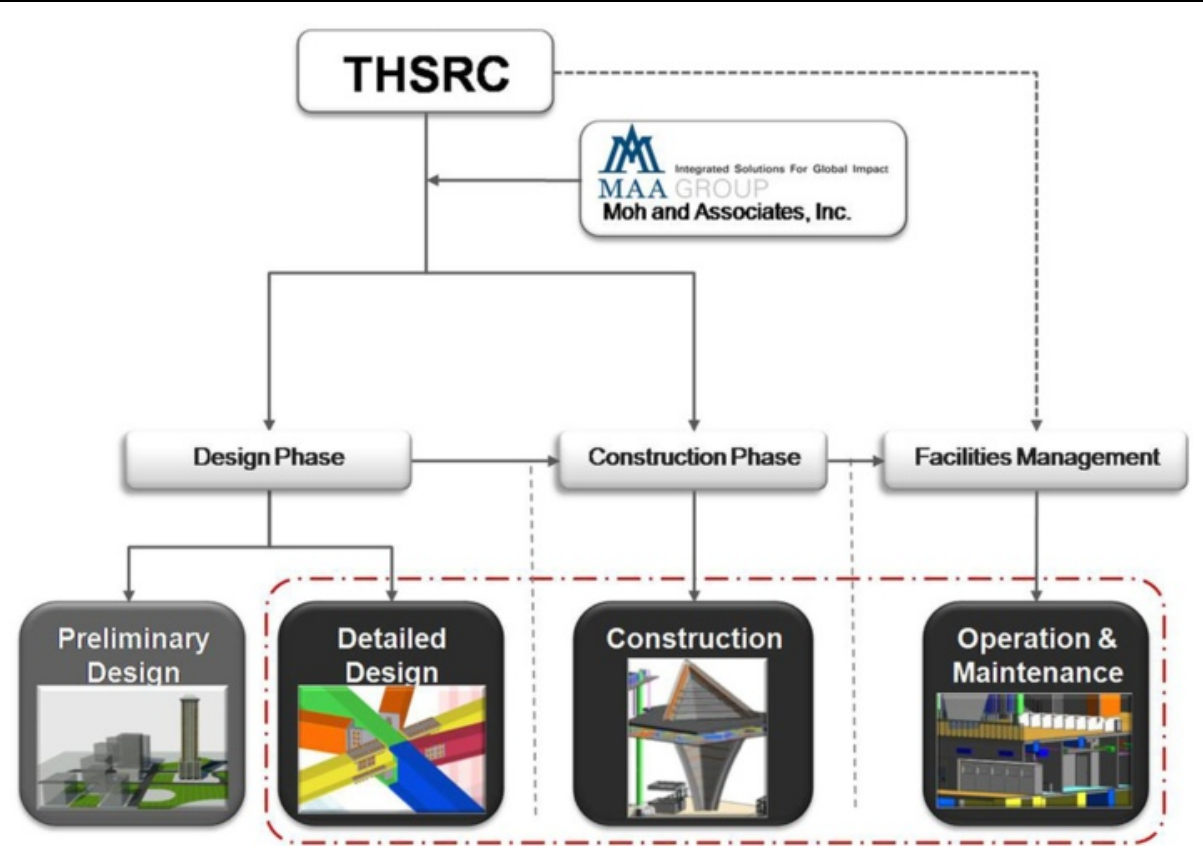

Figure 3 Organization chart.

structure of petal-like columns. BIM center provided the sections and perspective drawings generated from BIM model for the steel manufacturer to produce the curvature.

The production and application of integrated database in construction phase

The application of BIM technology for information synchronizing during the construction

Prior to the construction, BIM model was created according to the contract drawings approved by THSRC. The BIM model is used as a tool to coordinate various professional disciplines, to distribute integrated comments, to report errors and discrepancies in the drawings, and to generate clash detection report. Based on the clash report, THSRC reviewed the drawings submitted by the contractor, subcontractors and manufacturers in order to coordinate and correct the mistakes in the contract drawings before construction starts. Such a process allows for fewer field problems, enhanced construction quality, and a better control in the project procedure (shown as Figure 9).

The approved final version of BIM model was uploaded to the collaboration platform for THSRC and various parties to increase the efficiency of discussion. With the application of this platform, different sub-

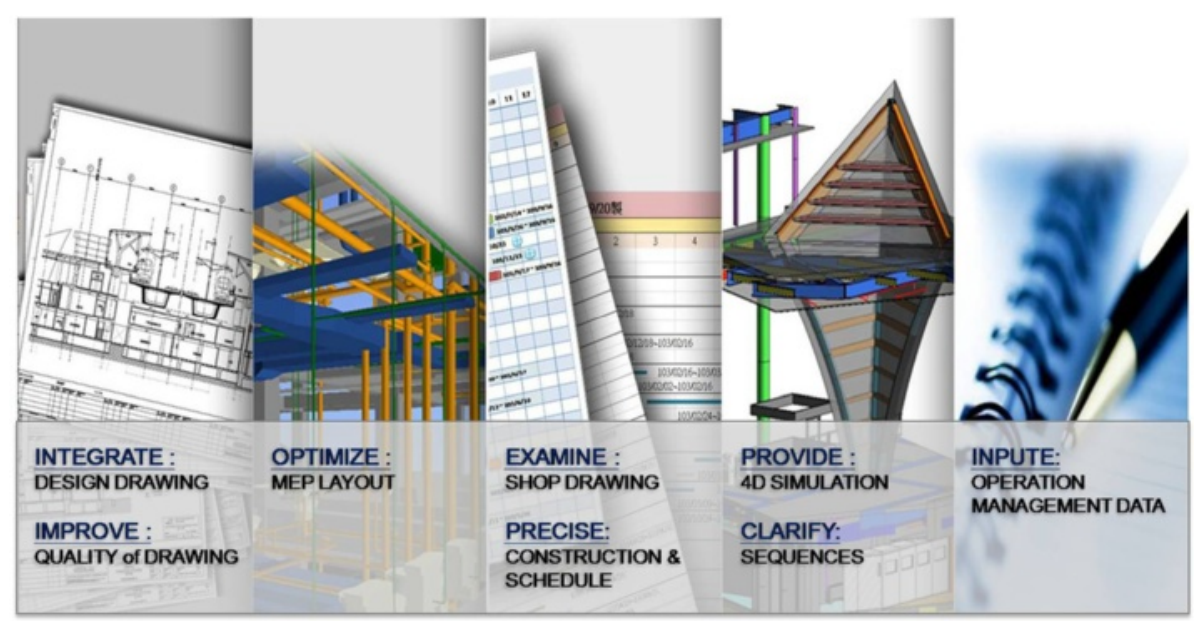

Figure 4 Project objectives. 


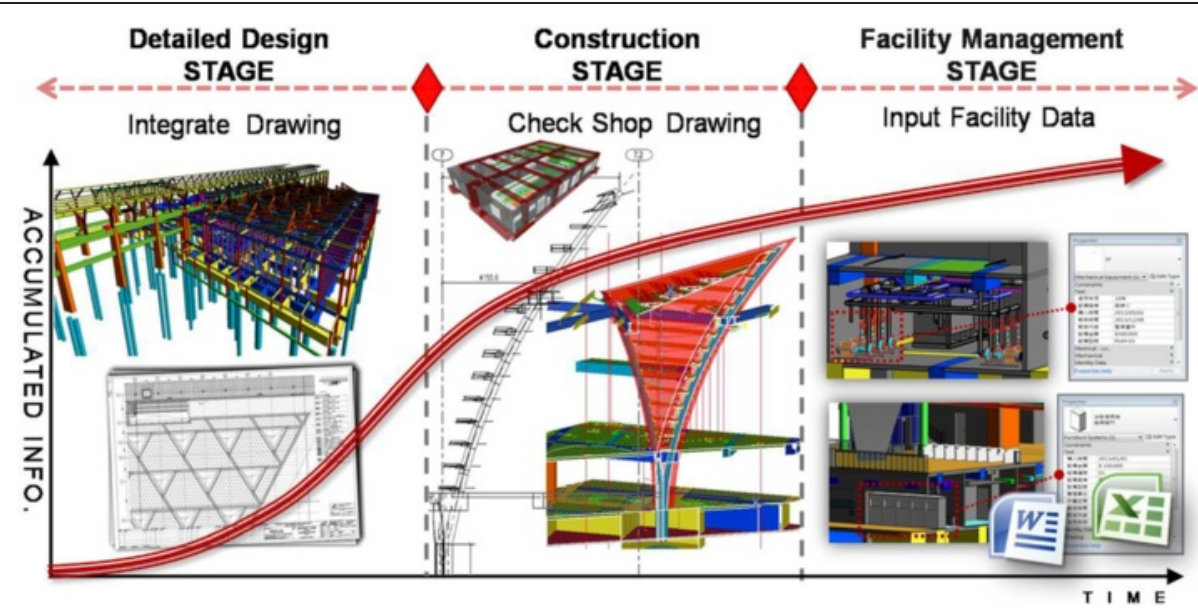

Figure 5 Building life cycle and BIM service flow chart.

contractors and manufacturers were able to discuss and resolve potential issues consistently.

To minimize the field problem and develop solutions, it is necessary to find out potential construction issues; for example, whether the elevation of piping is too high or too low, the clear space between drainage pipelines and surrounding objects, and the relationship between the positions of drain pipe and the elevation of catch basins (Figure 10).

Eighteen petal-like columns were designed to symbolize the characteristic of HSR Changhua station, twelve of them were located at the high ceiling lobby, and the other six were located at the maintenance area of the concourse floor slab. The design of petal-like columns creates the rhythm in the interior space and brings the image of local flower industry into the station. At early planning stage, the petal-like steel columns were integrated with interior decoration detailing, mechanical/electrical/piping and other design elements such as penetration of six petal-like steel columns through the floor slab, connection details of petal-like columns and beams supporting the floor, and the rebar arrangement between the steel column and concrete beam. Preventive discussions which reduce the frequency of design modification during construction are critical for early stage integration (shown as Figure 11).

During construction, drawings of petal-like columns and the ring girder from steel manufacturer were integrated with the sections generated from BIM model to examine the curvature of each petal-like columns and to corporate with architectural and MEP models for clash detection. Feedback loop was created between steel manufacturer and THSRC.

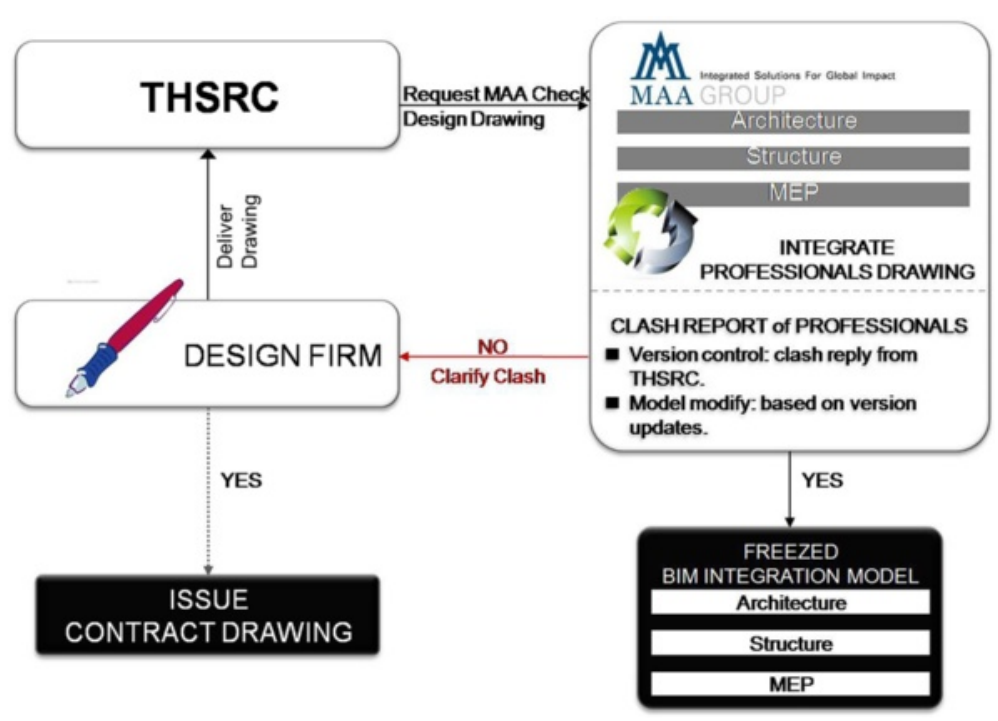

Figure 6 Design integration flowchart. 


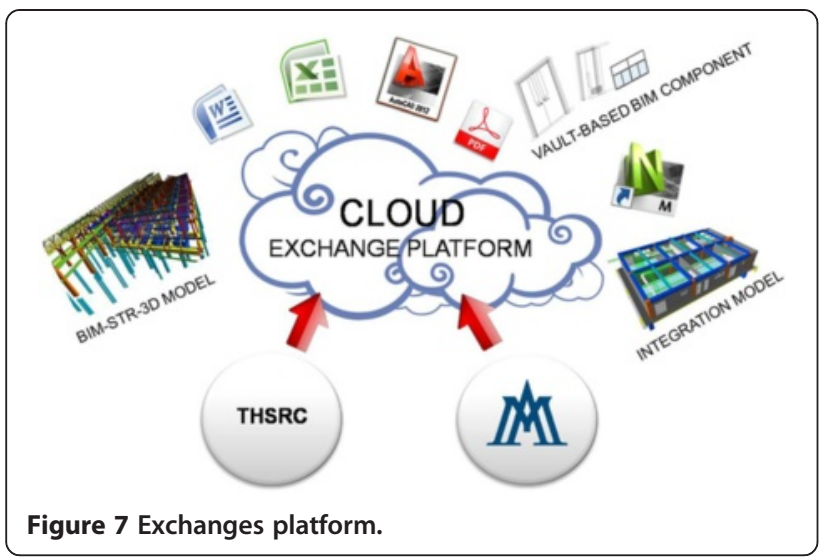

\section{The application of BIM technology for delivering clash} report during construction

Frozen BIM model provided a virtual platform to generate different perspective views for the steel manufacturer. The elevation of the ring girder was incorporated to the perspective views to improve the communication for resolving welding and on-site assembling issues. The ring girder elevation drawings from the manufacturer could also be included into the frozen structural BIM model and steel construction drawings for finding discrepancies. For THSRC, the project outcomes have improved greatly because of the capability of on-site checking and execution. Petal-like steel column checklist is shown as follows:

The clash report and construction report generated by the frozen BIM model were provided to THSRC as a reference for reviewing the construction drawing. The clash report list is shown as follows:

\section{Facility management and other benefits}

The BIM model was modified and corrected according to as-built drawings. To enhance the operation smoothness and management efficiency, it is crucial to understand owner's needs such as management method and to study the inspection and maintenance list during operation. MEP and operation facility information such as ticket gates and ticket vending machines were included in the as-built BIM model for different operation and maintenance sectors (shown as Figure 12). The statistic report can be derived from as-built BIM model by the customized parametric chart which includes information such as facility expiration date and maintenance schedule (shown as Figure 13).

Quantity report is another important task of the project. BIM model was tailored to generate the required outputs. Structural BIM model generates steel and concrete quantities; MEP BIM model generates pipe sizes and quantities. With these reports, THSRC was able to perform cross-check with the quantity report from design team, and thus to utilize the construction resource effectively, to reduce the waste, and to better control the budget (shown as Figure 14).

With the demand of animation film production, the ability of data interoperability in BIM technology helped to shorten the time of high quality animation production and to increase the accuracy of animation model by providing the corresponding data.

The 4D construction sequencing simulation is one of the other benefits of BIM model. It was made by integrating the construction information such as project schedule, work flow, site access, resource, and time to simulate the construction sequence. Visualized platform enabled the owner to discuss construction issues with contractors.

\section{Conclusions}

BIM technology was adopted throughout the planning stage to the construction phase for Taiwan High Speed Rail, Changhua Station construction project. This platform was used to improve communication, to integrate

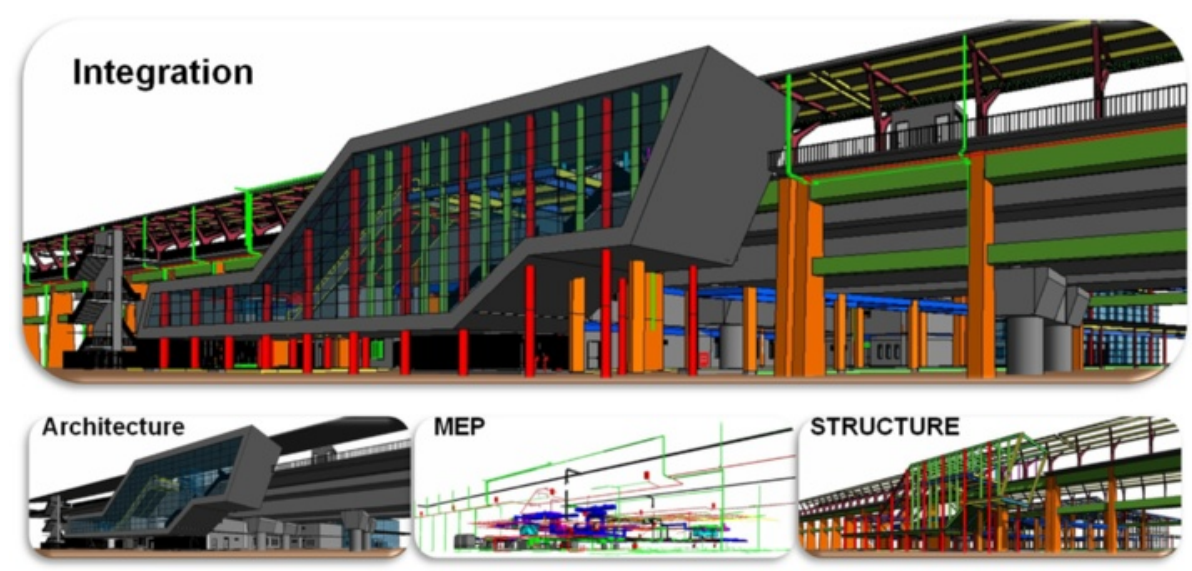

Figure 8 Integration BIM Models of Different Expertise. 


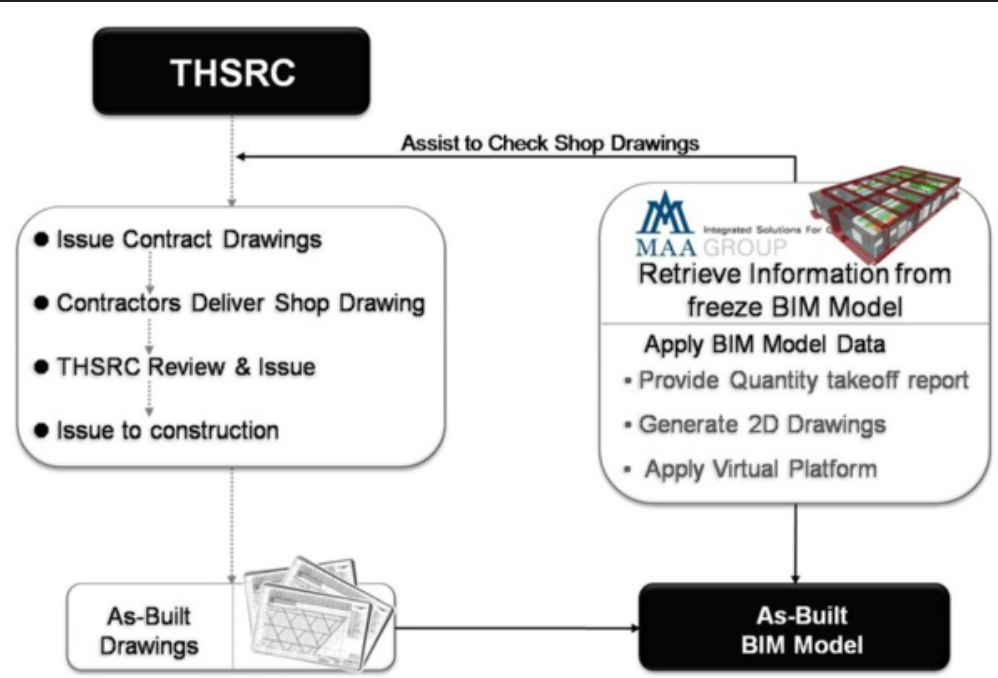

Figure 9 Construction integration flowchart.

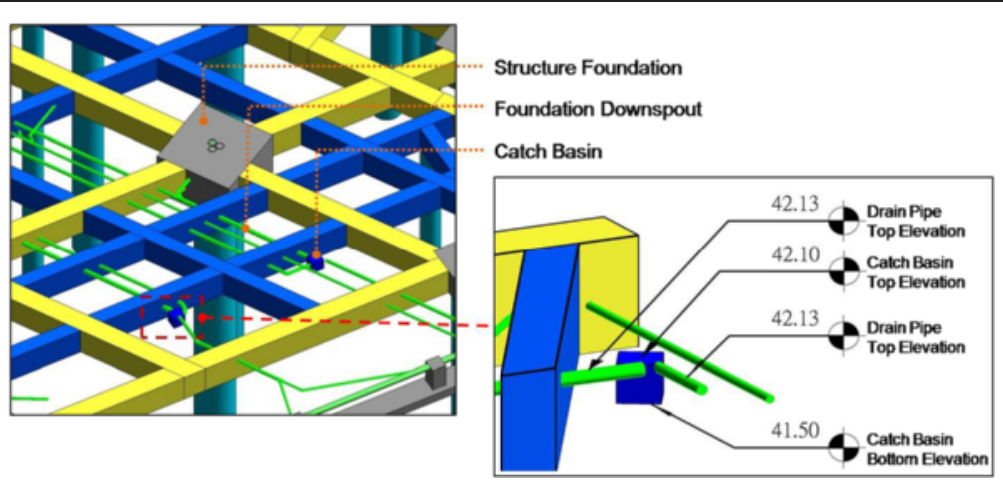

Figure 10 Foundation drainage elevation check point.

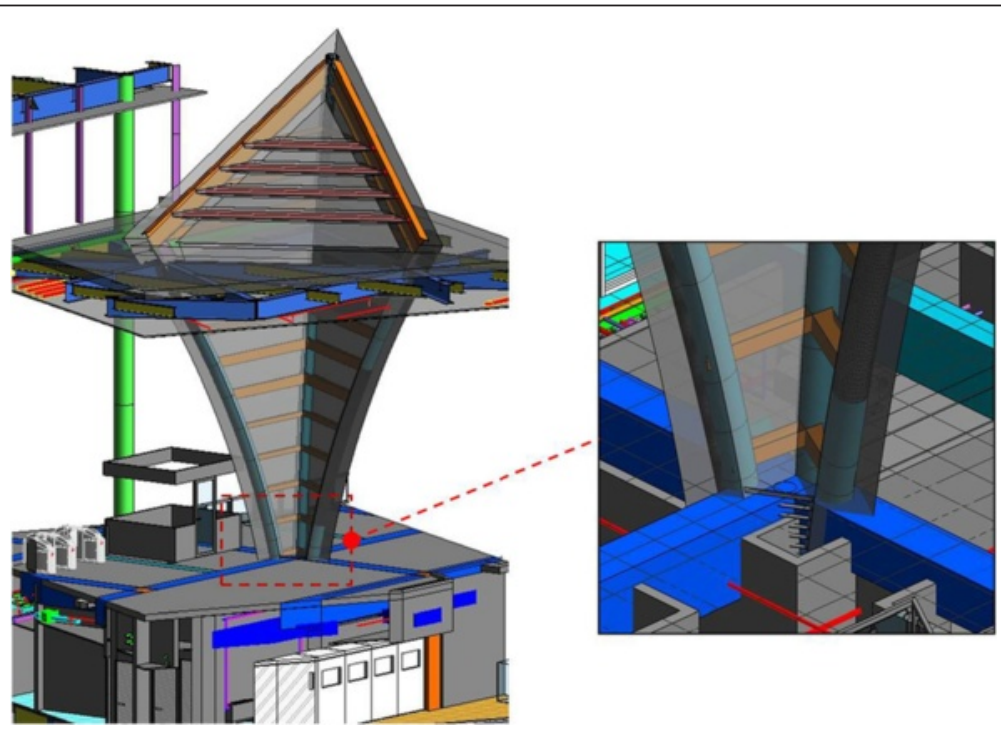

Figure 11 Integration of petal-like columns. 

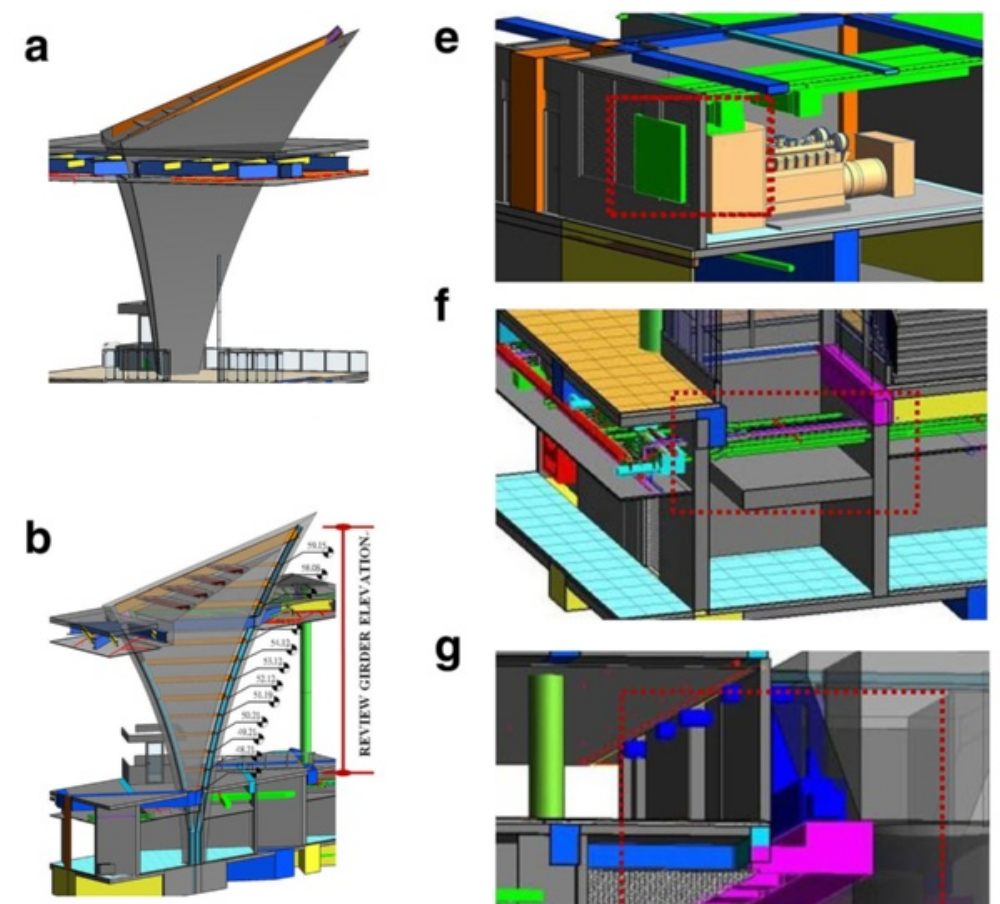

g
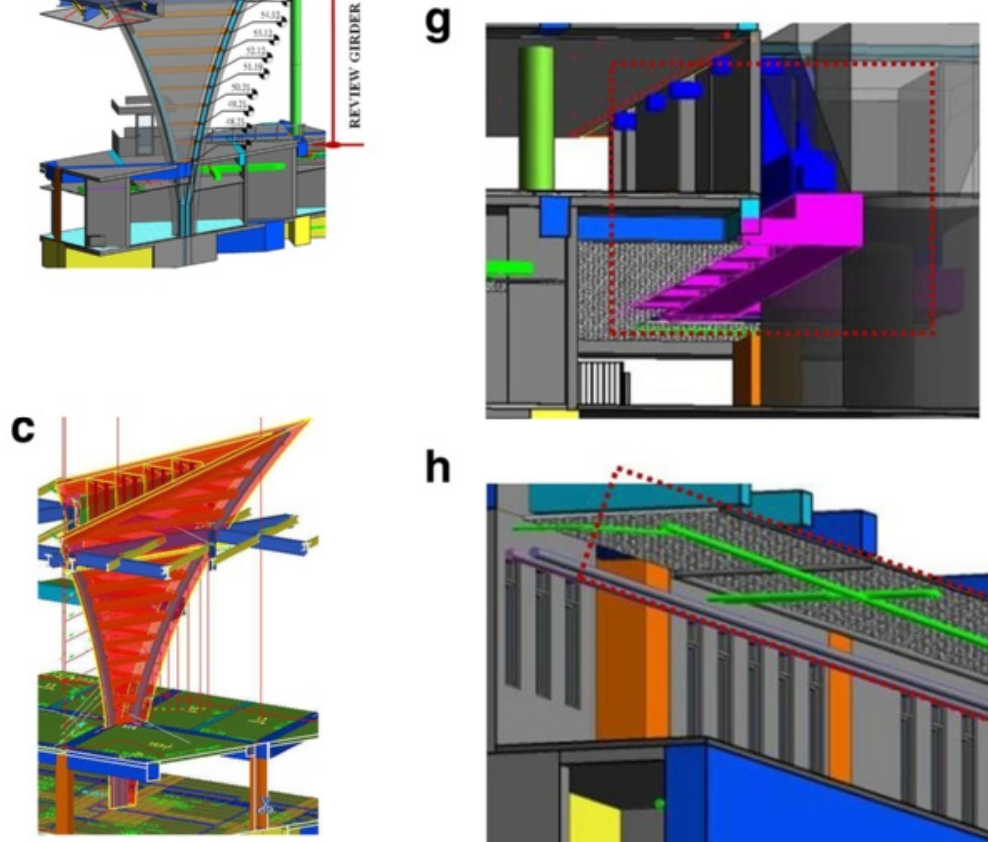

h

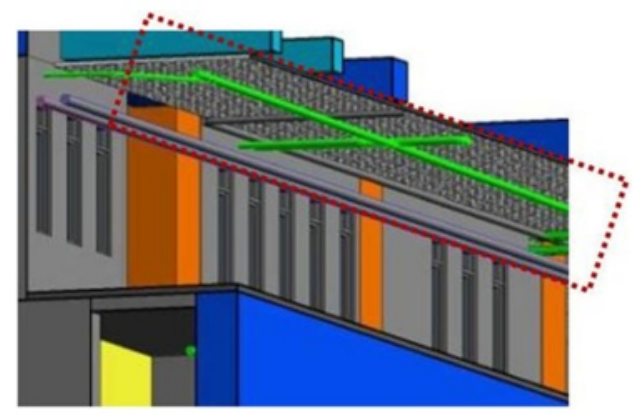

i
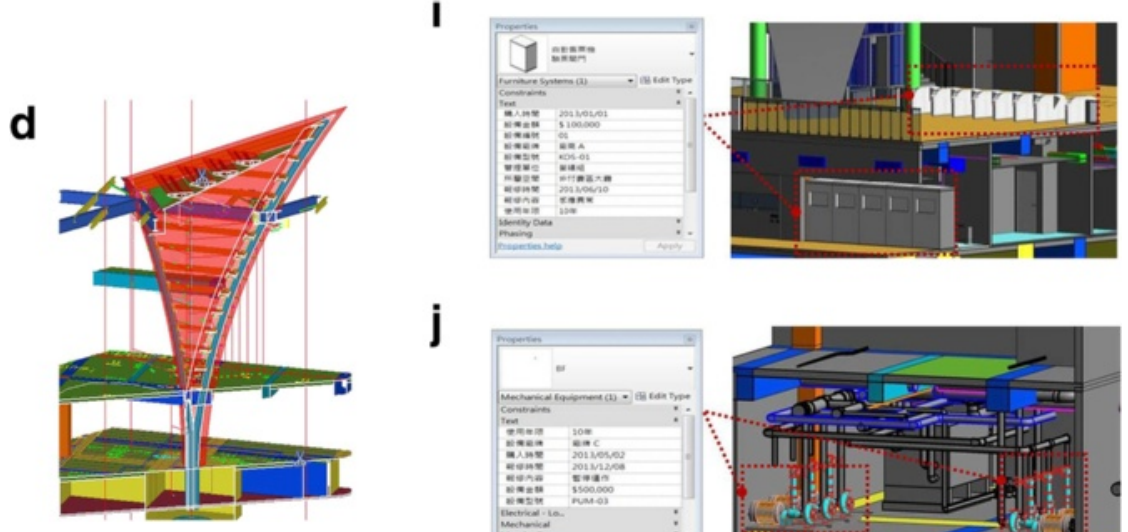

j

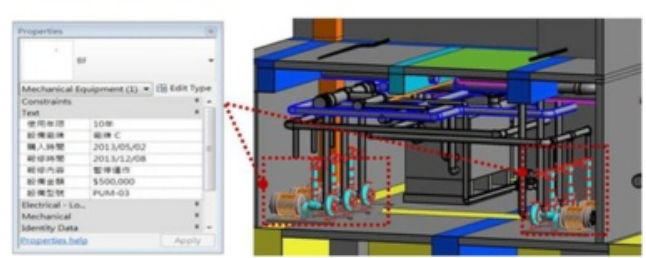

Figure 12 (See legend on next page.) 
(See figure on previous page.)

Figure 12 Facility management equipment. a. Integration of disciplines: clash detection of column A between structure and architecture. b. Assistance of reviewing girder elevation. c. Import 2D CAD into BIM structure model. d. Compare section of column A with 2D shop drawing. e. RM. No. 177 Generator RM. Incorrect position of exhaust vent and the louver. f. RM. No. 124 Station storage RM. MEP piping conflicts with the elevator pit. g. LINE 7.2-8.2 \& LINE B-E Ground level, duct and vent conflict with exsiting bridge. $\mathbf{h}$. Water Piping and duct elevation are below ceiling height. i. Operation Equipment maintenance data input. j. Mechanical Equipment maintenance data input.

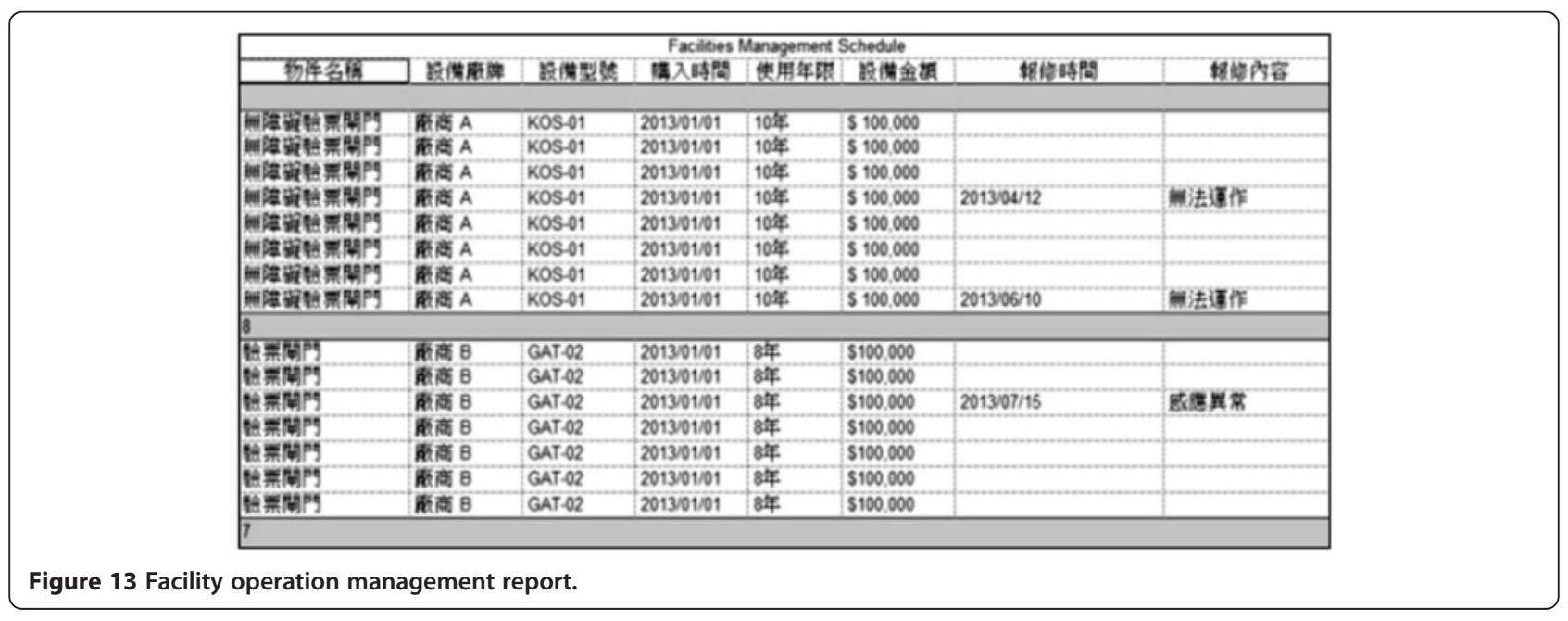

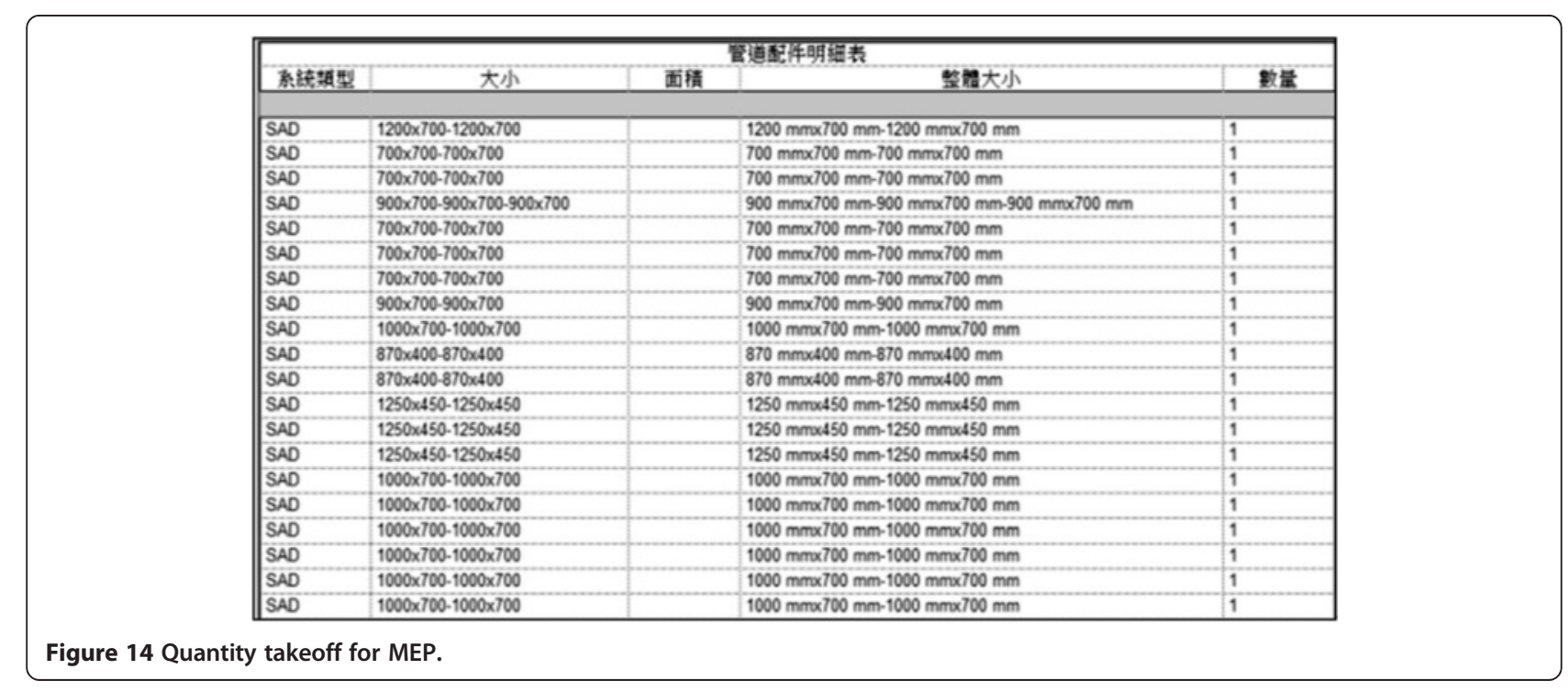


different versions of drawings and database, and to have each team member work effectively on the same pace. Each team member's design was coordinated to resolve interface issues and to implement clarifications on the drawings. The information gap and labeling errors were reduced significantly at the construction stage. The design delivery, construction quality, and project management were improved significantly.

The functions of BIM technology applied in this project at planning and construction stages are (shown as Figure 15):

1. Clarify the confusions between drawings (of architectural, structural and piping).

2. Provide solutions of conflicts of different disciplines (architecture, structure and MEP).

3. Create multi-discipline BIM model and provide 3D visual inspection for specific areas. Point out the problem area in advance. Reduce the blind spots of integrated 2D construction drawings.

4. Provide quantity reports of different disciplines for checking the quantity reports from the design team.

5. Provide collaboration platform for filing, database sharing and preview. Assist the management of various versions of drawings.
6. Help clarify the clash and difference between architectural drawing and construction drawing.

7. Provide the contractor relevant construction drawings and information.

8. Use 3D BIM model to resolve interface issues during construction.

9. Improve control over project progress, material control, and on-site preparation.

10. Provide as-built BIM model for facility management.

After completion of the project, the as-built BIM model was used for the operation and maintenance of HSR Changhua station by maintaining the useful and comprehensive information. The model was submitted according to owner and operator's requirements in a desired format to keep high performance management and to upgrade efficiency of maintenance work. In addition to the engineering applications throughout the complete lifecycle of the building, BIM technology provides additional benefits such as assistance to the production of high-quality animation, simulation of construction progress; and providing the visualized communication platform for different sectors to understand the project portfolio in an effective way. All these benefits lead the project to a greater business value. The application of BIM technology for HSR Changhua station improves the

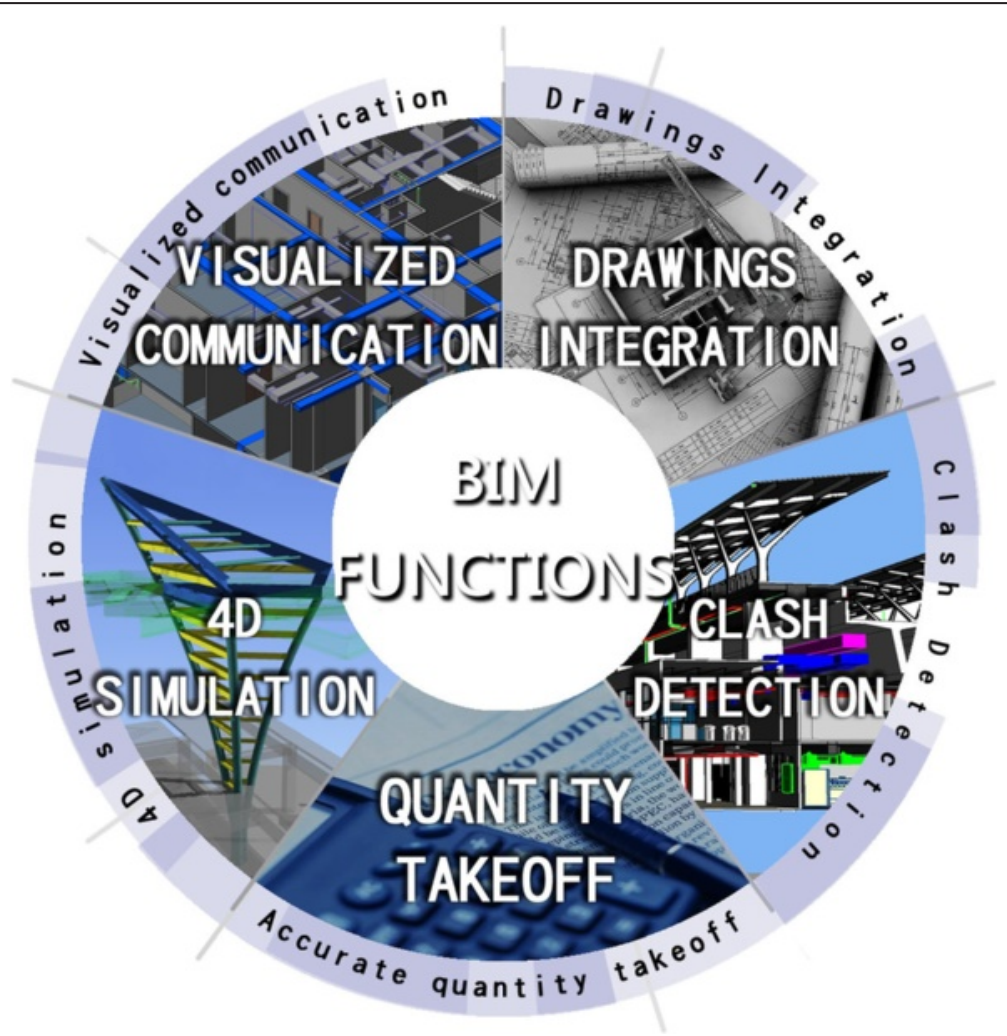

Figure 15 Functions of BIM technology. 
efficiency of the project management and enhances the quality of the construction that brings the project to complete on time.

\section{Competing interests}

The authors declare that they have no competing interests.

\section{Authors' contributions}

WL: BIM modelling, clash detection,4D simulation. SK: Project Manager. RM: Senior Vice President, Project Supervisor. RW: Site Resident Engineer. HH: Project Engineer. ZS: Project Engineer. All authors read and approved the final manuscript.

\section{Acknowledgement}

Taiwan High Speed Rail Corporation (THSRC) has commissioned Moh and Associates Inc.(MAA) to provide BIM service in the planning and consulting phases. Foremost, MAA would like to express our sincere gratitude to the directors of THSRC for their continuous support of the project. Besides, the authors would like to thank DANIEL CHU, WEN-JEN FANG, and ROGER LIN of THSRC and WEN-SHAN LIU, BEN LIN, S.C HUANG, and HSIANG-HSIANG YU of MAA for their assistance to develop this paper.

\section{Author details}

${ }^{1}$ Moh and Associates, Inc., BIM Mgmt. \& Engr. Integration Center, Taipei, Taiwan. ${ }^{2}$ Moh and Associates, Inc., Construction Supervision Dep., Taipei,

Taiwan. ${ }^{3}$ Taiwan High Speed Rail Corporation, Taipei, Taiwan.

Received: 6 March 2014 Accepted: 5 October 2014

Published online: 18 February 2015

\section{Submit your manuscript to a SpringerOpen ${ }^{\circ}$} journal and benefit from:

- Convenient online submission

- Rigorous peer review

- Immediate publication on acceptance

- Open access: articles freely available online

- High visibility within the field

- Retaining the copyright to your article 